See discussions, stats, and author profiles for this publication at: https://www.researchgate.net/publication/269520689

\title{
Environmental aspects of internal migration in Tanzania
}

Article in Population and Environment · December 2014

DOI: 10.1007/511111-014-0229-9

\section{CITATIONS}

16

4 authors, including:

\section{Maria Rita Testa}

Austrian Academy of Sciences

58 PUBLICATIONS 1,612 CITATIONS

SEE PROFILE

\section{READS}

689

Daniele Vignoli

University of Florence

87 PUBLICATIONS 1,233 CITATIONS

SEE PROFILE

Some of the authors of this publication are also working on these related projects:

Broject Births and other life goals: complementarity or competition? (BIRTHLIFE) View project

EU-FER, ECONOMIC UNCERTAINTY AND FERTILITY IN EUROPE View project 


\section{Environmental aspects of internal migration in Tanzania}

\section{Cristina Ocello, Alessandra Petrucci, Maria Rita Testa \& Daniele Vignoli}

Population and Environment

A Journal of Interdisciplinary Studies

ISSN 0199-0039

\section{Popul Environ}

DOI 10.1007/s11111-014-0229-9

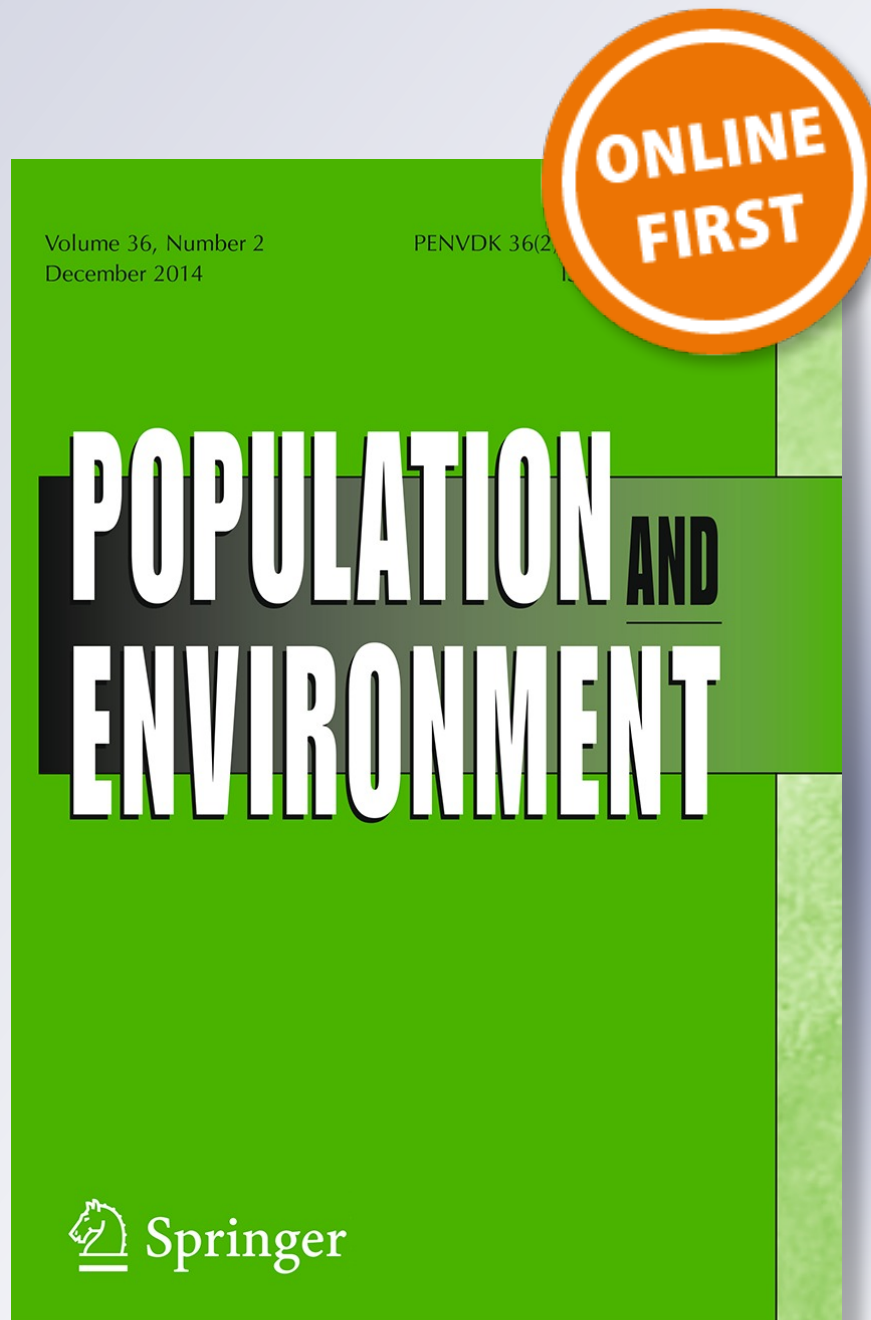

Springer

Springer 
Your article is protected by copyright and all rights are held exclusively by Springer Science +Business Media New York. This e-offprint is for personal use only and shall not be selfarchived in electronic repositories. If you wish to self-archive your article, please use the accepted manuscript version for posting on your own website. You may further deposit the accepted manuscript version in any repository, provided it is only made publicly available 12 months after official publication or later and provided acknowledgement is given to the original source of publication and a link is inserted to the published article on Springer's website. The link must be accompanied by the following text: "The final publication is available at link.springer.com". 


\title{
Environmental aspects of internal migration in Tanzania
}

\author{
Cristina Ocello • Alessandra Petrucci • \\ Maria Rita Testa $\cdot$ Daniele Vignoli
}

(C) Springer Science+Business Media New York 2014

\begin{abstract}
In recent years, the issue of the nexus of climate change and human migration has attracted a growing amount of interest among scholars and policy makers. Using individual-level data from the Tanzania National Panel Survey conducted in 2008-2009, we examine the roles played by droughts or floods, crop diseases, and severe water shortages in inter-district migration in Tanzania. Findings reveal that droughts or floods and crop diseases are associated with an overall decrease in the likelihood of inter-district mobility, providing support for the "environmental scarcity" hypothesis. Yet migration becomes a likely response to droughts and floods among individuals with no education suggesting mobility is a key livelihood strategy among those most disadvantaged. Future examination of domestic migration-environment processes at the individual-level is critical for informed policy and programs.
\end{abstract}

Keywords Migration - Climate change - Environment - Tanzania · Droughts and floods · Crop failure

C. Ocello $(\square)$

Department of Statistics, University of Florence, Florence, Italy

e-mail: cristina.ocello@gmail.com

C. Ocello

Clinical and Descriptive Epidemiology Unit, Cancer Prevention and Research Institute (ISPO),

Florence, Italy

A. Petrucci · D. Vignoli

Department of Statistics, Informatics, Applications (DiSIA), University of Florence, Florence, Italy

M. R. Testa

Wittgenstein Centre (IIASA, VID/ÖAW, WU), Vienna Institute of Demography, Austrian Academy of Sciences, Vienna, Austria 


\section{Introduction}

In recent years, climate change has become a major concern in the international context, and addressing climate challenges has become a priority for a wide range of actors worldwide. Mobility might be expected to increase following extreme events, such as storms, floods, and droughts; as well as in response to gradual changes in temperatures, precipitation, and sea levels. Yet predicting the effects of climate change on population movement remains a challenging task.

The literature on the link between environmental factors and migration offers two main perspectives on the question of how individuals and households will respond to these changes. The first predicts movement as adaptation to environmental change. Migration can indeed be seen as a coping mechanism or as a last-resort solution (McLeman and Smit 2006; Barnett and Webber 2010; Tacoli 2009), a proactive or reactive strategy (IOM 2008). ${ }^{1}$ For South America, Leighton noted that "the periodic drought and desertification plaguing northeast Brazil contributed to factors causing 3.4 million people to emigrate between 1960 and 1980" (Leighton 2006: 47). According to Kniveton et al. (2008), drought led to an increase in the number of individuals who engaged in short-term rural-rural migration. In addition, Afifi and Warner (2008) examined the impact of 13 different environmental factors across 172 countries of the world and found all had a significantly positive impact on migration flows.

The second perspective envisages a negative link between environmental factors and migration-the "environmental scarcity" hypothesis. For example, Findley (1994) investigated the consequences on migration of a series of droughts in Mali, 1983-1985. The results revealed a reduction in international migration during these drought years. More recently, Henry et al. (2003) studied the determinants of interprovincial migration flows in Burkina Faso, and found that droughts, rainfall variability, and severe soil degradation contributed only marginally to migration. In addition, the study of Paul (2005) provided empirical evidence that there was no out-migration from the villages affected by the tornado in the north-central Bangladesh on April 14, 2004.

However, environmentally induced migration is a complex phenomenon, as environmental change is usually identified as being only one of the many drivers of migration (Castles 2002). The decision to migrate is usually influenced not only by environmental factors, but also by cultural, economic, political, and social conditions. In each specific context, these interactions can increase or decrease migration (Black et al. 2011a; Piguet et al. 2011; Renaud et al. 2011). Moreover, the diversity in the types and forms of mobility, as well as the lack of mobility in regions affected by adverse environmental conditions, contribute to the complexity of this relationship (Tacoli 2011; Laczko and Aghazarm 2009).

This paper contributes to the ongoing discussion on the role of environmental factors in internal mobility in the African context (Van der Land and Hummel 2013; Msigwa and Mbongo 2013; Sow et al. 2014). Our goal in this paper is to investigate the effect of drought or floods, crop diseases, and severe water shortages on inter-

\footnotetext{
${ }^{1}$ A classical example of migration as a copying mechanism is given by seasonal mobility patterns.
} 
district migration in the United Republic of Tanzania, while controlling for several socio-demographic variables. The 2008-2009 Tanzania National Panel Survey (TZNPS) is a unique dataset, which allows us to examine the link between the environment and migration at the individual level, and to disentangle the interaction between this link and the socio-demographic characteristics of individuals, particularly educational levels given past evidence of the important association between migration and education in this setting (Striessnig et al. 2013). Tanzania provides an excellent case study for several reasons. First, the link between environment and migration has only very recently begun to be explored in this country, so this research offers an important baseline (see, for example, the analysis conducted by Liwenga et al., 2012). Second, Tanzania is highly vulnerable to droughts and floods (Raleigh et al. 2008), and a number of studies have found that climate change is already having a significant impact on the natural resources of the country (Agrawala et al. 2003; Majule 2008a, b; Liwenga et al. 2012). Third, in addition to having to cope with a large number of refugees arriving from neighboring countries (NBS 2006), Tanzania has recently experienced high levels of internal movements toward commercial and industrial areas (e.g., Dar es Salaam and Zanzibar town), or toward regions with new economic opportunities related to the growth of non-agricultural activities, such as mining or tourism (e.g., Arusha and Kagera regions).

\section{Data, measures, and selected sample}

We use data from the TZNPS, carried out by the Tanzania National Bureau of Statistics (NBS) from October 2008 to October 2009. The TZNPS is part of an ongoing project on the Living Standards Measurement Study-Integrated Surveys on Agriculture (LSMS-ISA), which is in turn part of the LSMS ${ }^{2}$ in the World Bank's Development Economic Research Group. The survey, scheduled to be repeated every 2 years, provides regular information on key development indicators useful for monitoring poverty dynamics in the country. Three different questionnaires were administered in the first baseline round used in our study: a multi-topic household questionnaire, a community questionnaire, and a questionnaire focused on agriculture.

Overall, 3,265 households with a total of 16,709 individuals were interviewed. This sample spanned all of the Tanzanian regions and districts (for details on the sampling strategy, see the document "Sample Design for the National Panel Survey"-April 2009).

The survey was not specifically designed to study migration movements and adverse environmental conditions. Thus, some standard assumptions were used to identify migrants as well as those potentially affected by adverse environmental conditions. A migrant was defined as a person aged 15 or older who had moved

\footnotetext{
2 The Living Standards Measurement Study (LSMS) is an ongoing research agenda within the Development Economics Research Group of the World Bank with the goal of promoting and improving the collection of household-level data in developing countries around the world. Further information can be found at the web site: www.worldbank.org/lsms.
} 
from one to another district in the 5 years prior to the interview. Migrants who moved into or out of the country were excluded from the analysis, given our focus on internal migration. The 5-year time frame was introduced to allow measurement of migration with the same temporal resolution available for environmental shocks, which had been recorded retrospectively for a period of up to 5 years before the interview. The age of 15 was chosen as a benchmark because it is reasonable to assume that people in Tanzania could start to live independently of their family of origin at around this age. This age has often been used in previous studies on similar topics (Henry et al. 2003, 2004; Gray and Mueller 2011).

Origin and destination districts were identified using the following two questions: "For how many years have you lived in this community?" and "From which district did you move?" Respondents living in the community for $<5$ years were considered migrants. The year of migration was computed by contrasting the interview year with the year in which the person began living in the district of interview. The destination and origin districts were derived from the first and second questions, respectively.

A specific section of the household questionnaire was devoted to the measurement of different shocks, environmental or otherwise, experienced in the 5 years prior to the interview. ${ }^{3}$ Respondents were asked: "Over the past 5 years, was your household severely affected negatively by any of the following events?" Eighteen different types of shocks are listed in the response options, and we focused on those most directly related to environmental events, such as drought and floods, crop diseases or crop pests, and severe water shortages. Respondents were also asked to rank the three most relevant shocks according to their level of severity and, as such, if multiple shocks were reported, we included that reported as most severe.

Since information on the years in which the three most severe shocks occurred was available, we were could time inter-district migration vis-a-vis the shock. Given our analytical focus on migration as a response to environmental stress, individuals who migrated before the environmental shocks were excluded from the analysis.

After this selection process, the analytical sample included 2,883 individuals aged 15 or above, $6 \%$ of whom migrated from one Tanzanian district to another in the 5-year period preceding the survey, i.e., 2004-2008.

Within the group of migrants, $42 \%$ reported having experienced any of the three selected environmental shocks prior to their inter-district move. In most of these cases $(82 \%)$, the shock had occurred one or 2 years before the inter-district migration, and in $51 \%$ the shock had occurred in the year immediately before the move. Consistent with some recent research that has demonstrated a lag time in migratory response to environmental shocks (Hunter et al. 2013), we considered internal migrations that occurred up to 5 years after the environmental shock. We are aware that a smaller temporal frame would provide a greater degree of certainty about the link between these two events.

\footnotetext{
3 All the questions of this section were administered to the household head or to most knowledgeable respondent of the household and provide information on different types of shocks which have negatively affected the household over the 5 years before the interview. We assumed that the information given by the household head is true for all the members of the household, which is a reasonable assumption, although a simplified one, given that in principle not all the household members were necessarily affected by the shock.
} 


\section{Model and results}

\section{Model specification}

Logistic regression models were used to estimate the impact of environmental shocks on inter-district migration. The response is a dichotomous variable $(1=$ migration $)$, as is each environmental shock $(1=$ shock $)$. Several sociodemographic variables are included: gender, age, level of education, marital status, and the number of children. Gender is a dummy variable $(1=$ female), and age is represented through a three-categorical variable: 15-29, 30-59 and 60 years and above. Three educational level categories are included: no education, primary education, and a high level of education (secondary or higher). The three educational categories reflect the structure of the Tanzania's educational system, as reported in Table 1.

Marital status is coded as a dummy variable ( $1=$ spouse living in household $)$ and four categories are created for number of children living in the household: zero, one, two or three, and four or more. The distributions of all variables are reported in Table 2. Most respondents were male, aged 30-59, with primary education and no children. On environmental shocks, $15 \%$ reported having experienced droughts or floods, $13 \%$ were affected by crop diseases or crop pests, and $22 \%$ had experienced severe water shortages. In addition, the estimates of the univariate logistic regression models, ${ }^{4}$ for each of the selected variables included in the final models, show that all the socio-demographic variables are statistically significant at $95 \%$ level of confidence in the prediction of internal migration, with the exception of gender. Moreover, the three environmental variables were also found to be statistically significant, but their effects on migration differed: experience of "drought or floods" and "crop disease or crop pests" shocks was negatively associated with internal migration, and thus appear to have acted as deterrents to inter-district mobility, whereas the "severe water shortage" shock demonstrated a positive association with internal migration.

Table 1 Structure of the formal education system in Tanzania

\begin{tabular}{llll}
\hline Level & Duration (years) & Entrance age & $\begin{array}{l}\text { Education variable } \\
\text { as coded in the logistic analysis }\end{array}$ \\
\hline Pre-primary education & 2 & 5 & No education $^{\mathrm{a}}$ \\
Primary education & 7 & 7 & Primary education \\
Lower secondary education & 4 & 14 & High level of education \\
Upper secondary education & 2 & 18 & High level of education \\
University education & 3 or more & 20 and over & High level of education \\
\hline
\end{tabular}

Source: NBS (2006); Tanzania National website-Education (http://www.tanzania.go.tz/home/pages/14)

${ }^{a}$ The category of no education also includes people who are illiterate. On the basis of the definition reported in the Population Census 2002 (NBS 2006), a person is classified as "literate" if he/she is able to read and write a simple statement

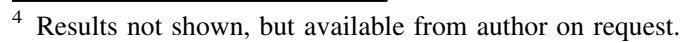


Table 2 Explanatory variables used in the logistic regression model: descriptive statistics

\begin{tabular}{ll}
\hline & Sample proportion (\%) \\
\hline Gender & 69 \\
Male & 31 \\
Female & \\
Age group & 22 \\
$15-29$ & 60 \\
$30-59$ & 18 \\
60 or above & \\
Level of education & 23 \\
No education & 60 \\
Primary education & 17 \\
Secondary education or higher educational level & 54 \\
Number of household-heads with a spouse living in the family & \\
Households by number of children & 60 \\
No children & 21 \\
1 child & 16 \\
2 or 3 children & 3 \\
4 or more children & \\
Households by type of environmental shock experienced & 15 \\
Drought or floods & 13 \\
Crop disease or crop pest & 22 \\
Severe water shortage & \\
\hline
\end{tabular}

Author's elaboration on 2008-2009 TZNPS data

Within the multivariate models, we used a robust variance estimator for clustered data which releases corrected standard errors of the coefficients ${ }^{5}$ by taking into account the intra-district correlation; i.e., the fact that people living in the same district are more similar than people living in different districts.

\section{Results}

The results of the multivariate logistic regression models are reported in Table 3 . Model I presents the estimates of the additive model, while Model II reports the estimates of the interaction model. In the end, we retained in the final model only the interaction terms which reached statistical significance (at $95 \%$ level of confidence). As is well-known, the odds ratios can be interpreted as the multiplicative effects of a one-unit increase in the predictor on the odds of the outcome (i.e., migration) relative to the reference outcome (i.e., no migration).

\footnotetext{
5 This approach specifies that the standard errors allow for (district) intra-group correlation, relaxing the usual requirement that the observations are independent: that is, the observations are independent across clusters (i.e., districts), but not within clusters.
} 
Table 3 Multivariate logistic regression models predicting internal migration in Tanzania

\begin{tabular}{|c|c|c|c|c|c|c|}
\hline \multirow[t]{2}{*}{ Variables } & \multicolumn{3}{|c|}{$\begin{array}{l}\text { MODEL I (additive } \\
\text { model) }\end{array}$} & \multicolumn{3}{|c|}{$\begin{array}{l}\text { MODEL II (interaction } \\
\text { model) }\end{array}$} \\
\hline & OR & SEs & $P>|z|$ & OR & SEs & $P>|\mathrm{z}|$ \\
\hline \multicolumn{7}{|l|}{ Socio-demographic variables } \\
\hline Gender (ref. male) & 1 & $(0.21)$ & 0.99 & 1.00 & $(0.21)$ & 0.99 \\
\hline \multicolumn{7}{|l|}{ Age (ref. 15-29) } \\
\hline $30-59$ & 0.37 & $(0.07)$ & 0.00 & 0.37 & $(0.07)$ & 0.00 \\
\hline 60 or above & 0.23 & $(0.09)$ & 0.00 & 0.25 & $(0.09)$ & 0.00 \\
\hline \multicolumn{7}{|l|}{ Education (ref. primary education) } \\
\hline No education & 0.66 & $(0.20)$ & 0.16 & 0.51 & $(0.18)$ & 0.05 \\
\hline Secondary education or higher educational level & 2.08 & $(0.43)$ & 0.00 & 2.05 & $(0.42)$ & 0.00 \\
\hline Married (ref. single) & 0.6 & $(0.16)$ & 0.06 & 0.60 & $(0.16)$ & 0.06 \\
\hline \multicolumn{7}{|l|}{ Number of children (ref. no child) } \\
\hline 1 & 0.19 & $(0.06)$ & 0.00 & 0.19 & $(0.06)$ & 0.00 \\
\hline 2 or 3 & 0.18 & $(0.08)$ & 0.00 & 0.18 & $(0.08)$ & 0.00 \\
\hline 4 or more & 0.27 & $(0.19)$ & 0.06 & 0.28 & $(0.20)$ & 0.07 \\
\hline \multicolumn{7}{|l|}{ Environmental shocks within past 5 years } \\
\hline Drought or floods & 0.51 & $(0.16)$ & 0.03 & 0.36 & $(0.15)$ & 0.02 \\
\hline Crop disease or crop pests & 0.26 & $(0.11)$ & 0.00 & 0.26 & $(0.11)$ & 0.00 \\
\hline Severe water shortage & 0.91 & $(0.19)$ & 0.66 & 0.91 & $(0.19)$ & 0.64 \\
\hline Interaction: no education $\times$ drought or floods & - & - & - & 3.87 & $(2.59)$ & 0.04 \\
\hline Interaction: high education $\times$ drought or floods & - & - & - & 1.11 & $(0.81)$ & 0.88 \\
\hline Number of observations & 2,883 & & & 2,883 & & \\
\hline
\end{tabular}

Author's elaboration on 2008-2009 TZNPS data

Estimates are adjusted for intra-cluster (i.e., district) correlation. Standard errors are given in parenthesis

In agreement with the results of the univariate models, the results of Model I suggest the environmental shocks of droughts/floods or of crop diseases/pests acted as deterrents to inter-district migration. Specifically, net of the model's control variables, respondents who experienced drought or floods were $49 \%$ less likely to migrate, and those who experienced crop disease or crop pests were $74 \%$ less likely to migrate, as contrasted to respondents not experiencing such shocks (Model I). By contrast, the experience of a severe water shortage did not significantly influence inter-district migration.

In Model II, the estimates for the environmental shocks' effects on migration suggest migration may be a coping strategy particularly of importance to those lacking education. Indeed, even if the environmental shocks of droughts/floods acted as deterrent to inter-district migration net of the model's control variables, the interaction between the level of education and this environmental shock reveals a higher propensity to move (about four times as high) for individuals with no education contrasted with individuals with primary education. In addition, although 
highly educated respondents are more likely to migrate in general, their probability of migration was not additionally shaped by environmental strain.

In agreement with the results of Model I, the results of Model II show the same effects for the environmental shocks: droughts/floods and crop diseases/pests acted as deterrents to inter-district migration, while the experience of a severe water shortage did not significantly influence mobility.

On controls, both for Models I and II, the demographic variables are all statistically significant, with the exception of gender. Moreover, their effect in terms of both magnitude and sign is almost identical in the two models, with (Model II) and without interaction terms (Model I). Age decreases the propensity to move, which peaks at the ages 15-29 and then declines; being married and having children in the household were negatively associated with the propensity to move. We also found that the probability of migration was about twice as high among respondents with high levels of education as contrasted with those with primary education (Models I and II). By contrast, respondents with no education tended to stay in their district (this effect was not statistically significant in Model I).

\section{Concluding remarks}

The number of studies examining the link between climate change and human migration has grown significantly in recent years. But the results have not yet yielded generalisable conclusions. The research presented here represents one of the first attempts to study the link between internal migration and environmental change in the United Republic of Tanzania using household-level survey data.

Conventional narratives posit that displacements will inevitably occur under climate change (e.g., Myers 2002; Warner et al. 2009). To the contrary, this research provides empirical evidence that adverse environmental conditions actually decrease internal mobility in Tanzania: Being exposed to droughts or floods and to crop diseases or crop pests had a negative and statistically significant effect on the likelihood of inter-district migration. This result remained even after we controlled for a set of socio-demographic variables.

In line with research by Black et al. (2011b), our results reveal that mobility is selective. Barriers to mobility include lack of social, economic, and human resources. Thus, the effects of environmental change on migration may vary across social groups. Indeed, our findings suggest the link between migration and adverse environmental conditions differs by educational level of the potential migrant. Importantly, least-educated respondents were more likely to respond to environmental shocks through migration, suggesting an important coping strategy among those most disadvantaged. This finding is only partially consistent with Black et al. (2011b), who described the poorest and least mobile people as a "trapped population." They found that impoverished people face a double set of risks: They are unable to move away from environmental threats, and their lack of capital makes them especially vulnerable to environmental changes.

A possible explanation for the negative association between migration and environmental shocks lies in government policies to improve resilience. For 
example, the National Strategy for Growth and Poverty Reduction was designed to stimulate economic growth in the affected regions and to improve the quality of life and the social well being of the affected people. Recently, other strategies like rainfall-based insurance have been proposed (e.g., Sarris et al. 2006).

In line with a number of recent studies on environmentally induced population mobility (Halliday 2006; Gray 2009; Massey et al. 2010; Black et al. 2011a), our empirical analysis underscores two important insights: that the relationship between climate change and migration is not always unidirectional, and that adverse environmental conditions might discourage rather than encourage internal migration. An important extension of the current analysis would supplement the included subjective measures of environmental shocks with analogous measures derived from the official statistics. Another extension will involve the second wave of the TZNPS, allowing a longitudinal perspective. This approach will facilitate understanding of whether the migration-environment association appears to reflect a proactive or a reactive strategy.

In all, this research contributes to support the "environmental scarcity" hypothesis illustrating that droughts or floods and crop diseases are associated with an overall decrease in the likelihood of internal migration in Tanzania. The complexity revealed also challenges the idea of a simple, unidirectional link between environmental factors and migration.

\section{References}

Afifi, T., \& Warner, K. (2008). The impact of environmental degradation on migration flows across countries. Working Paper N. 5/2008, UNU-EHS, Bonn.

Agrawala, S., et al. (2003). Development and climate change in Tanzania: Focus Mount Kilimanjaro. Paris: OECD.

Barnett, J., \& Webber, M. (2010). Accommodating migration to promote adaptation to climate change. Policy research working paper 5270. Washington, DC: World Bank.

Black, R., Adger, W. N., Arnell, N. W., Dercon, S., Geddes, A., \& Thomas, D. (2011a). The effect of environmental change on human migration. Global Environmental Change, 21S, S3-S11.

Black, R., Adger, W. N., Arnell, N. W., Dercon, S., Geddes, A., \& Thomas, D. (2011b). Foresight: Migration and global environmental change, final project report. London: The Government Office for Science.

Castles, S. (2002). Environmental change and forced migration: Making sense of the debate, (vol 70). New issues in refugee research-UNHCR research paper.

Findley, S. E. (1994). Does drought increase migration? A study of migration from rural Mali during the 1983-85 drought. International Migration Review, 28(3), 539-553.

Gray, C. L. (2009). Environment land and rural out-migration in the southern ecuadorian andes. World Development, 37(2), 457-468.

Gray, C., \& Mueller, V. (2011). Drought and population mobility in rural Ethiopia. World Development, 40(1), 134-145.

Halliday, T. (2006). Migration, risk, and liquidity constraints in El Salvador. Economic Development and Cultural Change, 54(4), 893-925.

Henry, S., Boyle, P., \& Lambin, E. F. (2003). Modelling inter-provincial migration in Burkina Faso, West Africa: The role of socio-demographic and environmental factors. Applied Geography, 23, 115-136.

Henry, S., Schoumaker, B., \& Beauchemin, C. (2004). The impact of rainfall on the first out-migration: A multilevel event-history analysis in Burkina Faso. Population and Environment, 25(5), 423-460. 
Hunter, L. M., Murray, S., \& Riosmena, F. (2013). Rainfall patterns and US migration from rural Mexico. International Migration Review, 47(4), 874-909.

IOM International Organization for Migration. (2008). World migration report 2008. Geneva: IOM.

Kniveton, D., Schmidt-Verkerk, K., Smith, C., \& Black, R. (2008). Climate change and migration: Improving methodologies to estimate flows. IOM migration research series paper No. 33 Geneva: International Organization for Migration.

Laczko, F., \& Aghazarm, C. (2009). Migration, environment and climate change: Assessing the evidence. Geneva: International Organization for Migration (IOM).

Leighton, M. (2006). Desertification and migration. In P. M. Johnson, K. Mayrand \& M. Paquin (Eds.), Governing global desertification (pp. 43-58). London: Ashgate.

Liwenga E.T., Kwezi L., \& Afifi T. (2012). “When the rain falls” project. Case study: Tanzania. Results from Same District, Kilimanjaro Region. Report. No. 6. Bonn. United Nation University. Institute for Environmental and Human Security (UNU-EHS).

Majule, A. E., (2008). Climate change and variability: Impacts on agriculture and water resource and implications for livelihoods in selected basins. Towards climate change adaptation. InWEnt-Int, Weiterbildung und Entwicklung GmbH 978-3- 939394-28-0.

Majule, A. E., et al. (2008). Strengthening local agric. Innovation systems in less and more favoured areas of Tanzania and Malawi to adapt to climate change and variability: Perceptions. Impacts, vulnerability and adaptation. Res. Abstracts. Issue No. 3: Sokoine University of Agric.: ISBN: 9987-38-9.

Massey, D. S., Axinn, W. G., \& Ghimire, D. J. (2010). Environmental change and out-migration: evidence from Nepal. Population Environmental, 32(2), 109-136.

McLeman, R., \& Smit, B. (2006). Migration as an adaptation to climate change. Climatic Change, 76(1-2), 31-53.

Msigwa, R. E., \& Mbongo, J. E. (2013). Determinants of internal migration in Tanzania. Journal of Economics and Sustainable Development, 4(9), 28-35.

Myers, N. (2002). Environmental refugees: a growing phenomenon of the 21st century. Philosophical Transactions of the Royal Society, London-B, 357(1420), 609-613.

National Bureau of Statistics (NBS). (2006), Population census 2002, analytical report, (Vol X). Dar es Salaam.

Paul, B. K. (2005). Evidence against disaster-induced migration: The 2004 tornado in north-central Bangladesh. Disasters, 29(4), 370-385.

Piguet, E., Pécoud, A., \& de Guchteneire, P. (2011). Migration and climate change: An overview. Working paper No. 79-Centre on Migration Policy and Society, University of Oxford.

Raleigh, C., Jordan, L., \& Salehyan, I. (2008). Assessing the impact of climate change on migration and conflict. Washington, DC: World Bank Group. http://siteresources.worldbank.org/EXTSOCIAL DEVELOPMENT/Resources/SDCCWorkingPaper_MigrationandConflict.pdf

Renaud, F. G., Dun, O., Warner, K., \& Bogardi, J. (2011). A decision framework for environmentally induced migration. International Migration, 49(S1), e5-e29. doi:10.1111/j.1468-2435.2010.00678.x.

Sarris, A., Karfakis, P., \& Christiaensen, L. (2006). Producer demand and welfare benefits of rainfall insurance in Tanzania. FAO commodity and trade policy research, working paper No. 18.

Sow, P., Adaawen, Stephen A., \& Scheffran, J. (2014). Migration, social demands and environmental change amongst the Frafra of Northern Ghana and the Biali in Northern Benin. Sustainability, 6(1), 375-398.

Striessnig, E., Lutz, W., \& Patt, A. G. (2013). Effects of educational attainment on climate risk vulnerability. Ecology and Society, 18(1), 16. doi:10.5751/ES-05252-180116.

Tacoli, C. (2009). Crisis or adaptation? Migration and climate change in a context of high mobility. Environment and Urbanization, 21(2), 515-525.

Tacoli, C. (2011). CR2: The links between environmental change and migration: A livelihoods approach. Foresight: Migration and global environmental change. London: International Institute for Environment and Development.

Van der Land, V., \& Hummel, D. (2013). Vulnerability and the role of education in environmentally induced migration in Mali and Senegal. Ecology and Society, 18(4), 14. doi:10.5751/ES-05830180414.

Warner, K., Ehrhart, C., de Sherbinin, A., Adamo, S., \& Chai-Onn, T. (2009). In search of shelterMapping the effects of climate change on human migration and displacement. CARE/CIESIN/ UNHCR/UNU-EHS/World Bank. 